Exploring malignancies: narcissism and paranoia today

\title{
Barry Richards
}

Professor Barry Richards

Faculty of Media and Communication

Bournemouth University

Fern Barrow

POOLE

BH12 5BB

UK

brichards@bournemouth.ac.uk

07966182895

01202965331 
Exploring malignancies: narcissism and paranoia today

\author{
ABSTRACT \\ Lasch’s 1978 study of the 'culture of narcissism' is discussed as a model socio- \\ psychoanalytic inquiry. In fragmented societies however the search for an \\ encompassing diagnosis is less useful than a strategy of identifying states of mind \\ active in specific situations. In studying more malignant phenomena, paranoid states \\ are important, especially in their combination with narcissism. Hofstadter’s 1964 \\ essay on the paranoid 'style' is a key reference point. Comparing Lasch and \\ Hofstadter invites a consideration of broad issues concerning the relations between \\ culture and psyche, and between leaders and followers. The paper ends with a short \\ commentary on narcissistic and paranoid states of mind in the case of President \\ Trump.
}




\title{
Exploring malignancies: narcissism and paranoia today
}

\author{
Keywords: states of mind, narcissism, paranoia, malignancy, Trump
}

\section{The re-emergence of narcissism}

This century has seen a growing interest in the relevance of the concept of narcissism to understanding contemporary society and politics, both in public discourse and in academic work. In social psychology, for example, Twenge and Campbell (2009) have written of the 'narcissism epidemic'. In management studies and in political psychology, the dangers of the narcissistic leader are being examined, using different theoretical perspectives. Some of this inquiry is psychoanalytically-informed, as in Mark Stein's study of the outcomes of narcissistic leadership in business (Stein, 2013), or Alveson and Gabriel's commentary on grandiosity in management discourse (Alveson and Gabriel, 2016). More of it, however, is based on social-psychological models of identity and cognition, linked with psychometric, trait-based definitions of what constitutes ‘narcissism’ (e.g. Cichocka, 2016; Hatemi \& Fazekas, forthcoming).

One reason for this interest is socio-technological: the arrival of the web and then of social media, the consequences of which of course are enormously complex and mixed, but if focused on in a particular way can be seen as inducing and supporting the expression of narcissistic traits. The online universe, and social media platforms in particular, can be seen as promoting the superficiality of interpersonal exchanges and 
the preoccupation with self-presentation which are often taken as characteristic of the narcissistic personality. How much these effects outweigh the benefits of those same platforms in facilitating positive exchanges between people, in creating networks and offering new modes of self-development, remains unclear. What is more clear is that a number of the most disturbing aspects of $21^{\text {st }}$ century politics seem to involve narcissism, at least when that is understood psychoanalytically as a profound disturbance of character rooted in defences against vulnerability and fear (and in Kleinian terms, against envy - Klein, 19 ; Segal, 1983). Inviting deployment of the term 'narcissistic' are some of the autocratic national rulers of different varieties whom we are now aware of across the globe, though this is not a new phenomenon. What is probably new, however, is the irruption of political styles drawing on gross narcissism into long-standing liberal democracies, typically enacted by leaders often described as 'populist'. Also, we might suggest that in the psychology of contemporary terrorisms, the omnipotent delusions of both Islamist and extreme rightwing terrorists, and their supporters, point to the importance of narcissistic phantasy in driving this current threat, which is another new development.

We have though been here before. The American historian Christopher Lasch, wrote 'The Culture of Narcissism', back in 1978. It had considerable impact, including on the present author. This was in the context of efforts in the 1970s by some people on the political Left, and by some feminists, to use psychoanalysis in developing a psychosocial and politically engaged approach to the study of the contemporary world. Some of the questions which were felt to need answering were these: why across the Western world had the radical movements of the 1970s, political and cultural, faded away without having produced political change? Why, despite the 
experience of Nazism, was racism such a force in the world? How was a progressive movement that might help produce a more equal and radically better society going to develop? The search for answers led some people to create a second wave of FreudoMarxism, building on the Frankfurt School project of fusing Freud and Marx, by turning to the post-Freudian developments in psychoanalysis (where the choice between Lacanian or Kleinian and object-relational approaches divided the field). Insightful though some of the work of Frankfurt School theorists was, it was becoming clear that neither classical Freud nor classical Marx were adequate starting points for understanding the emerging complexities of late capitalism.

\section{'The Culture of Narcissism'}

Lasch's book didn’t directly address any of these questions. But it opened up a new way of thinking psychosocially which could address them. It showed how a psychoanalytic understanding of emotional development based in the post-Freudian work of Melanie Klein and others could be linked with an account of cultural change to produce a diagnosis of our times. It did so with a rare combination of scholarship, passionate engagement and arresting style. It is worth briefly rehearsing the central thesis of this book. Lasch argued that the family has been displaced from its fundamental role in the shaping of personality by the growth of dependence on the state and on professional expertise, and by the insertion of consumer culture into all areas of life such that emotional development comes to take place in, and to be regulated by, the world of consumer goods and its images of pleasure, freedom and perfection. In the ideal model of development posited by psychoanalysis, stable parental figures provide the developing mind of the infant and child with both nurture 
and constraint, love and discipline, and it is in gratitude to them that the child comes to identify with authority and to internalize the capacity to regulate its own emotions, especially its destructiveness. Through continuing experience of their love and protection, the child is secure with them and able to accept their shortcomings, so as to experience them as whole, integrated 'objects', to use the language of objectrelations theory. Experience of these good external objects provides the template for the development of stable internal objects, flawed but fundamentally good, which are the core building blocks for the development both of the ego and the superego, and thereby of a strong and rich sense of self and identity. Mental health therefore rests on identifications with parental figures formed in a context where love and authority are fused together.

In the course of the twentieth-century, Lasch proposed, this possibility for goodenough emotional development was being undermined by a collapse in parental authority, stemming from the declining confidence which parents had in relation to the tasks of parenting, and the reduced legitimacy of their role. The hedonistic imperatives of consumer culture flooded into the family home, while from the early decades of the century onwards many of the new welfare professions had sought to scientise the tasks of parenting, or by other means to bring them under the hegemony of the experts, subordinating the role of parents. So from different directions the role of the family as the primary unit of cultural reproduction was undermined, and parents withdrew from the work of character-building. As a consequence of this 'socialisation of reproduction', as Lasch called it, the developing psyche is less able to internalise integrated parental objects, and lacking this internal foundation for security is vulnerable to extreme anxiety, and to feelings of abandonment and emptiness. 
Lasch links this account of cultural change to the rise of the borderline and especially narcissistic personality disorders described by psychoanalytic and psychiatric clinicians in the second half of the twentieth century (his main references were to Kernberg, Kohut and Klein). The psyche’s defensive response to the sense of abandonment was to retreat into a grandiose self, to defend against both its sense of vulnerability in the world and its lack of control over its own unintegrated aggressive impulses, which were not managed by containing parental introjects. Hence the development of the culture of narcissism, as the expression of this major historical shift in the modal character structure, or at least a typical character structure, of the USA.

\section{The perfect market and the failing family}

The book was a best-seller, and Lasch was invited to Camp David to discuss it with President Jimmy Carter, as he sought advice from various quarters while trying to write a presidential speech which exhorted people to consume less oil. The purpose of the speech was to set out a new energy policy, aimed at reducing American dependence on foreign oil by imposing import quotas, but Carter linked the need for this policy to the idea of a general crisis in American society and culture, and it became known as the 'crisis of confidence' speech. While it has no explicit links to Lasch's work, we might see the choice of the words 'crisis' and 'confidence' as consistent with, if not derived from, his analysis. In short, Carter was calling the American people not to fill the emptiness of their lives with material goods, and was 
trying to return them to a more morally-confident and future-oriented outlook (Carter, 1979).

Lasch's book also attracted much criticism, including that from some feminists who believed (wrongly, I think) that it was a conservative lament for patriarchy. It can also be read as a critique of the welfare state and/or of therapeutic culture, although again I think that would not be an accurate characterization of it. In any event, as we moved into the 1980s it seemed as if the most dangerous narcissistic fantasies were not the ones which could in some way be connected with dependency-inducing state welfarism. Instead, in that period of growing neo-liberal influence, a diagnosis of deep narcissism was more easily attached to hostility to state-supported welfare. It was the hatred of the state which offered the most comfortable political home for the narcissistic self. It would be hard to find a more clear expression of narcissism in political philosophy than the ideas of Hayek (1960) and those others who propose the image of the self-sufficient sovereign individual who needs nothing from anyone except the opportunity to exercise free choice in a free and perfect market. This is the grandiose monadic self of neo-liberalism, the complement to the grandiose collective self of totalitarianisms, where the narcissistic phantasy is organized around images of the ideal, purified group, whether defined by race, class or nation.

So Lasch's critique, while it still threw a strong light onto aspects of the consumer society, seemed to lose some relevance as an analysis of politics. However it deserves some re-examination now there has been a revival of interest in the category of narcissism as a force in politics. Its strength is that it goes to the roots of individual development in early experiences of parenting to explain how identities and values 
are changing - how dysfunctions and lacunae in parenting produce, in conjunction with other social changes, certain kinds of adult individual, who then go on to increase the effect in their own parenting - an inter-generational minimization of the self, to borrow from the title of his subsequent book (Lasch, 1984). This is a very deeply psychosocial model, using a concept of narcissism which is much broader and deeper than that conveyed in the term's everyday meaning, in which it refers to qualities of manifest egotism and self-centredness. In Lasch’s psychoanalyticallybased view, it is an unconscious structure of the self, one which can generate a range of different outward behaviours and 'personalities'. It can be expressed anywhere in the political spectrum, attached to any ideology, or none at all. Overall, what we have in The Culture of Narcissism is a perhaps unique attempt to capture the full psychosocial arc of change, from the unconscious of the adult parent through the primitive terrors and defences of the infantile psyche to the unconscious of the next adult generation, with that inter- and intrapsychic process being linked to a historian's narrative of emergent practices and value shifts in welfare, education, gender relations, the arts and sport.

\section{Syndrome or style}

While we may still learn from its insights and its method, however, there are reasons why this analysis does not give an adequate platform for the study of society and politics forty years on. One is that that the diagnostic impulse, the search for an overarching psychological characterization of a society, was perhaps always bound to fail. While, as Lasch showed, many diverse social phenomena may be fed by the same basic psychic source, there are on the other hand many different psychic drivers 
which can be channeled into and feed the same social phenomenon. Moreover, the cultural pluralism driven by globalization has now progressed to such an extent that the idea of an encompassing diagnosis of a society is much less plausible than it was in the 1970s.

Rather than striving to offer comprehensive diagnoses of a culture, or seeking to identify the dominant personality type of a society, it might therefore be better for us to try and be clear about what psychic needs and unconscious phantasies are most active in particular situations and around particular policy issues. We might thus be able to offer more nuanced analyses and even to inform more effective responses and interventions around those situations or issues. This more case-based approach would call for in-depth studies of the states of mind active in specific contexts.

Narcissistic states of mind would be certain to figure prominently in such an approach. As noted earlier, it seems that narcissism - in its psychodynamic meaning as a state of mind not a set of behavioural traits - is a key concept in understanding a range of current phenomena. However, especially when we are looking at the more malignant of these phenomena, we need to see it in combination with other states of mind. Foremost amongst these is one long recognized to be of major importance in politics, namely paranoia. A very valuable reference point here is to be found in the work of another American historian, Richard Hofstadter, who was an influence on Lasch. He wrote an essay back in 1964, called 'The paranoid style in American politics', which is an early and eloquent analysis of conspiracy theories, but more broadly should be seen as a founding text of political psychology. In it he describes a number of influential movements in American political history which have depended 
on beliefs that society is at risk from malign and hidden forces, which must be expunged from the body politic. McCarthyist anti-communism was his most recent example, but he goes back to the eighteenth and nineteenth centuries to examine powerful currents of paranoid feeling about Illuminati, Masons, Catholics and Jesuits.

\section{The pathology of normalcy}

He calls it a 'paranoid' style 'because no other word adequately evokes the sense of heated exaggeration, suspiciousness, and conspiratorial fantasy' (op. cit., p. 77) that he observes. He is however at pains to say that he does not imply that the believers in conspiracy theories are all of unsound mind; rather, these theories become politically dangerous when they are taken up by 'more or less normal people' (loc. cit.). This is a surprising statement in view of what else he has to say. Hofstadter claims no psychological expertise, yet reaches the same conclusion which a psychoanalyst would about the dynamics of conspiracy theorizing in the mind of the individual. He notes how descriptions of the threat often stress the extraordinary power and resolve of the enemy, as well as his embodiment of diabolical evil, and writes:

'It is hard to resist the conclusion that this enemy is on many counts a projection of the self; both the ideal and the unacceptable aspects of the self are attributed to him.' (op. cit., p. 85)

It is clear then that he understood the delusional element of the paranoid outlook, yet he pulled back from the conclusion that the involvement of 'normal people' in these delusions meant that normality could be pathological. This reluctance to pass 
judgment on the soundness of the public mind reflects a widespread tendency in the social sciences, as in common sense, to equate statistical 'normality' with health, as if collective human judgment cannot, by definition, be insane. One of the psychiatric panels commissioned to assess Anders Breivik concluded that because his views were shared by a section of the public they could not be regarded as delusions. '.. there is an ideological subculture that share the subject's ideological and political perceptions. One finds, therefore, no basis for delusional disorder' (Torrissen and Aspass, 2012, S. 21.5.2). We might see this tendency as the complement to that strand of critical rhetoric which proposes that 'normality' is the real madness. In order to revise Hofstadter's position, it is not necessary to undertake that sort of Laingian-style reversal whereby normality as a whole becomes the pathology. But understanding the cultural supports of destructive movements or toxic leadership must involve accepting the pathological dimensions of everyday normality.

This point highlights an important difference between Hofstadter and Lasch, one which is especially relevant to the relationship between leadership and psychological disturbance. In Lasch’s analysis, the culture is narcissistic either because increasing numbers of individual people are of narcissistic personality, or have strong narcissistic traits, or because such people are becoming increasingly dominant and influential. In Hofstadter's analysis, there is no inquiry into the psychic roots and individual bases of the paranoid tendency; indeed as we have just discussed there is a wish not to posit any such roots. The paranoia is a 'style' that is widespread in political culture, and can be adopted by people pursuing a wide range of political goals, but it does not mean that they as individuals have paranoid personalities. 
Both writers would recognise the role of leaders in pulling more people into their narcissistic or paranoid causes, but they differ in the extent to which they see society and the individual as direct reflections of each other. For Lasch (though I'm simplifying him here), culture is personality writ large; society and psyche are tightly woven together, if not in lockstep. For Hofstadter, politics is a style which people of different personalities may at times adopt, or a narrative we can opt into but which does not define us as persons.

This could be seen as a difference of degree rather than an absolute one, but it is important. It is linked to the old question of whether we get the leaders 'we deserve', i.e. those who reflect our own psyches, or whether leaders can shape their following in their own image. There are reasons to be drawn towards both these answers. The saying that we get the leaders we deserve asks that we the public accept some responsibility for the nature and actions of our leaders, while the idea that leaders make their own followers strikes a more hopeful note - it suggests that to make a better society we may not need to reconfigure the entire national psyche from bottom up, just to have the right leadership (though looking at the present choices facing us in the UK, that could be seen as a significant restriction). However the leader will need some starting base in the public in question, which concurs with Hofstadter's observation that the paranoid mentality ‘..may be a persistent psychic phenomenon, more or less constantly affecting a modest minority of the population' (op. cit., p.86).

\section{Paranoid delusions}


These broader questions aside, it will hopefully be evident why a focus on paranoid states of mind is essential to understanding a lot of what is going in the world. In the era of the Cold War, the paranoid foundations of McCarthyism as described by Hofstadter were at work in both public perceptions and in policy elites, and similar mindsets continue to be a force around the world today. They survive in, for example, the direct descendant of Cold War communism, KimilsungismKimjongilism, as illustrated in these statements of Kim Jong-Un in his 2017 New Year address to the North Korean nation:

'...the imperialists' nuclear war threats, which were growing more wicked day by day... the enemy's vicious schemes to isolate and suffocate our country...the enemy grew more blatant in their obstructive schemes...the enemy's sinister and pernicious schemes to check the warm and pure-hearted aspiration of our people who follow the Party single-heartedly and to alienate the Party from them...the United States and its vassal forces keep on [presenting a] nuclear threat...' (Kim, 2017)

In its strenuous superlatives about the Party and the people, this text also swells with corporatized narcissism, interlaced with the paranoia of the quotes above. And as with narcissism, it is important to differentiate a psychoanalytic understanding of 'paranoid' states from some everyday usages of the term. Paranoid states are part of a defensive construction in which unintegrated internal bad objects are projected onto external objects, which are then consequently experienced as evil and threatening. The Kleinian term ‘paranoid-schizoid position’ conveys the dependency of paranoid states on the mechanism of splitting, though the process of splitting is an omnipresent 
one which has a huge range of adverse outcomes not all of which are paranoid. Some psychosocial studies of politics have rightly highlighted the role of splitting as a primitive defence underpinning the process of 'Othering', that is an aversion to some social group defined as different and 'other' to one's own. This is widely understood to be central to racism and many other forms of inter-group conflict, and there may be some tendency for this much broader category to blur with the idea of 'paranoia'.

On the more rigorous definition of paranoia, however, there is much more specificity to it than aversion or hostility, and the sense of rivalry or displacement with which those feelings are often associated. There is an acute, often overwhelming sense of threat, based, as Hofstadter showed and Kim Jong-Un illustrates, on persistent and often highly elaborated delusional beliefs that the 'Other' is an evil and powerful force that must and will attack oneself or one's group. The conviction that preemptive or retaliatory attack is necessary is then easily incorporated into the delusional system. The delusions may be triggered by events in the external world, and may in part be isomorphic to aspects of external reality, but are fundamentally intrapsychic in origin.

I have brought in the category of paranoia, and twinned Lasch with his former tutor Hofstadter, because while the concept of narcissism may get us a long way in understanding some of the destructive dynamics at work in politics, especially in leadership both domestically and internationally, to understand deep malignancy better we have to bring in the concept of paranoia. When a grandiose self gets paranoid, the potential for narcissism to generate very destructive behaviour is greatly increased. The narcissistic rage at being opposed or constrained, the omnipotent 
readiness to choose confrontation, the lack of real empathy for others - all such narcissistic traits and potentials can then be in the service of an uninhibited attack on others, whether in office politics, in military offensive or in civil war. The narcissistic capacity for delusion can serve the pursuit of a conspiracy theory, and when a political leader becomes immersed in a conspiracy theory then the risk of others following and of a conflict escalating is high.

Readers more familiar with the psychoanalytic literature in this area are likely to have noted that the concepts of malignant or negative narcissism, as developed in the 1970s by the psychoanalysts Otto Kernberg (1975) in the US and Herbert Rosenfeld (197 ) in Britain, and by others, capture this convergence of narcissism and paranoia as part of a broader picture in which there is a perverse idealisation of destructive parts of the self. To examine that clinical literature more closely, and to consider its relevance for politics, would be the task of another paper. It would also represent a different approach to that taken here, in which a case has been made for focussing on specific (and possibly transient) states of mind in specific contexts, rather than applying more comprehensive diagnostic formulations - which is not possible where there is insufficient knowledge about an individual, and not advisable when we are dealing with psychic drivers of political behaviour at a group level.

The word limit here also prevents consideration of a broader issue in psychoanalytic theory, that of the interpenetration of the concepts of narcissism and paranoia, as indicated by Hanna Segal's suggestion that the paranoid-schizoid position is a 'narcissistic' one (Segal, 1983). 


\section{The case of Donald Trump}

There is now an extensive literature of 'Trump Studies', in both academia and media commentary, which makes free use of the term 'narcissism' in relation to the President, based on his public persona. However appropriate it may be, descriptively, this may not always be helpful in that it may be deployed as a pejorative term requiring no further explanation or understanding. Even when this literature is working with an understanding of narcissism as a primitive defence against terror, it may still be politically counterproductive, in that it does not usually examine the states of mind of his supporters and the grievances which brought him to power, while implicitly demeaning them.

I referred earlier to the two approaches to leader-follower relations, distinguished by whether the leader is seen as the expression or the definer of the public psyche. Trump appears to fit both models. I have suggested elsewhere (Author removed, 2016) that there may well be a large and long-standing reservoir of narcissism amongst the American public, an inflated sense of self typically linked to a nationalist identity. Though it is a defence against an underlying anxiety and vulnerability, this aggrandised self was able for many decades to feed itself on the experience of the wealth and power of the United States. However, 9/11 and shifts in the geo-political landscape this century have challenged that power, and brought the anxiety more to the surface. As a consequence, the narcissistic defence has assumed in some people a more aggressive quality, more dependent on the primitive processes of denial and splitting. Trump’s personality probably being very much built around that kind of defence, he was able to sense the growing constituency in the US for a more strident 
and desperate nationalism, and he set out to evoke and strengthen that constituency. Once his campaign for the nomination was under way, it gave some legitimacy to that more aggressive defence, and drew more people towards it.

There is a rather stark contrast here with President Carter's very different wish mentioned earlier to reshape the narcissistic defence thirty-seven years previously, at a time when American narcissism was challenged by the realisation of its increasing dependence on imported oil, and thereby on foreign governments.

It is important to note that nationalism is not the only card in Trump's hand. His rejection of the restraints imposed by the rules of civility was also important in building his support (Lunbeck, 2017), appealing as it does to a key feature of the narcissistic personality, which is the intolerance of the challenge which social rules pose to the omnipotence of the grandiose self. This is where some of the valorisation of authenticity, crystallised in the 1960s counter-culture, ended up, as a bellicose demand to be as rude and offensive as one wished.

It is also important to note that nationalism does not necessarily depend, psychologically, on narcissistic defences, and even where it does, it is not necessarily a bad thing. It depends on the content of the narcissistic identification with the idealised image of the nation. If the nation is idealised as a stronghold of liberal democracy, civility and fairness, then a narcissistic identification with it could result in a substantive commitment to those values and a strong sense of responsible citizenship. At the level of how people behave, narcissism is not always altogether a bad thing. 
In the case of Trumpism, though, it is hard to discern the better qualities of nationalism. However, there might be some mitigation of his presidency in that he does not appear to be subject to strongly paranoid states of mind. In his business career he has been endlessly aggressive, impulsive and manipulative, and driven by a desire to beat everybody (Kranish and Fisher, 2016). His fear is of failure, not of a powerful force which is out to get him. For example, his claims that the MSM (mainstream media) are constantly attacking him appear to be part of a strategy to neutralise their inevitable criticism of him and to reshape Presidential communications with the public. He has no ideology, and his narcissistic delusions leave little space for more paranoid ones. He believes he is emperor of a world in which friends and enemies are, over time, largely interchangeable, at his will. It is a jungle in which all people are obviously at each others' throats, and while opponents must always be watched and fought, there is no parallel universe in which he is in the crosshairs.

If this is correct, the lobbies which are America's equivalent to Kim Jong-Un should not capture the President's ear, and his foreign policy, while probably chaotic and dangerous, will not be tied to the wilful prosecution of conflict with a delusionallyelaborated enemy. While we wait to see how that is going to work out, some longerterm questions continue to demand our attention: questions about the societal facilitators of narcissistic and paranoid states of mind, and about how to develop the emotional capital and other societal resources for the containment of these and other toxic states, in order to minimise the likelihood of a malignant leader acquiring a substantial following. 


\section{$\underline{\text { References }}$}

Alveson, M. and Gabriel, Y. (2016) Grandiosity in contemporary management and education. Management Learning 47(4): 464-473.

Carter, J. (1979) Energy and National Goals: Address to the Nation.

July 15, 1979. https://www.jimmycarterlibrary.gov/documents/speeches/energy-

crisis.phtml, accessed 28 June 2017.

Cichocka, A. (2016) Understanding defensive and secure in-group positivity: The role of collective narcissism. Eur. Rev. of Soc. Psychol. 27: 283-317.

Hatemi, P. \& Fazekas, Z. (in prep.) Narcissism and the political behavior of mass publics.

Hayek, F. (1960) The Constitution of Liberty. Chicago: University of Chicago Press, 2011.

Hofstadter, R. (1964) The paranoid style in American politics. Harper’s Magazine November 1964.

Kernberg, O. (1975) Borderline Conditions and Pathological Narcissism. New York: Jason Aronson.

Kim, Jong-Un (2017) Respected Supreme Leader Kim Jong Un made the New Year Address for 2017.

http://www.ncnk.org/sites/default/files/KJU_2017_New_Years_Address.pdf, accessed 28 June 2017

Klein, M. (1957) Envy and Gratitude. London: Tavistock. 
Kranish, M. and Fisher, M. (2016) Trump Revealed. The definitive biography of the $45^{\text {th }}$. President. London: Simon and Schuster.

Lasch. C. (1979) The Culture of Narcissism. American life an in age of diminishing expectations. New York: Norton.

Lasch, C. (1984) The Minimal Self. Psychic survival in troubled times. New York: Norton.

Lunbeck, E. (2017) The narcissistic appeal of Donald Trump. Paper presented at ESRC seminar on 'Narcissism and destructive leadership’, London, 16 June 2017. Rosenfeld, H. (1971) A clinical approach to the psycho-analytic theory of the life and death instincts: an investigation into the aggressive aspects of narcissism. Int. J. Psycho-Anal. 52: 169-178.

Segal, H. (1983) Some clinical implications of Melanie Klein’s work. Int. J. PsychoAnal. 66: 201-213.

Stein, M. (2013) When does narcissistic leadership become problematic? Dick Fuld at Lehman Brothers. J. Management Inquiry 22(3), 282-293.

Torrissen, T. and Aspass, A. (2012) Anders Behring Breivik Psychiatric Report 201204-10. Court Psychiatric Statement to the Oslo District Court.

https://sites.google.com/site/breivikreport/documents/anders-breivik-psychiatricreport-2012-04-10, accessed 28 June 2017.

Twenge, J.M and Campbell, W.K. (2009) The Narcissism Epidemic. Living in the age of entitlement. New York: Simon \& Schuster. 